\title{
Tooth-A Key Aid in Establishing Identity of Deceased Individuals
}

\section{Jain $\mathbf{N}^{*}$}

Manav Rachna Dental College, Delhi- Surajkund Road, Sector-43, Faridabad, India

\begin{abstract}
Forensic odontology is the branch of dentistry which aids in identifying human remains after homicides, accidents, wars or natural calamities. Forensic science has long been dependent on fingerprints or some identification mark on the body of a deceased individual. But in the absence of such evidence dental indicators assist successfully in the identification process. The study of teeth and the surrounding tissues of the oral cavity in order to establish the identity of a victim are known as dental profiling. Teeth can play a vital role in estimating the age, sex, race, socio-economic status, personal habits, oral and systemic health, occupation and dietary status of an individual. Various methods like radiographic imaging, dentin translucency, amino acid racemization, chromosomal analysis, barr bodies, amelogenin protein analysis, cementum annulations have made dentist an essential part of forensics.
\end{abstract}

Keywords: Forensic odontology; Dental profiling; Racemization; Barr bodies; Amelogenin; Cementum annulations

\section{Introduction}

Tooth varies in its form in different individuals and undergoes wear, trauma, disease and professional manipulation during the course of one's life. But being the most enduring part of the body and it can withstand degradation even after death of an individual [1]. Hence tooth is considered to be very crucial in dental identification during the investigative procedures especially in the absence of any other evidence. The chief tenet behind dental identification is the comparison of postmortem records with antemortem records like dental history, study models, radiographs, photographs etc. to confirm identity [2]. But if there is no antemortem dental record of the person present then postmortem dental profiling is done.

Dental profile comprises of a group of specific individual characteristics related to the teeth and surrounding tissues. These characteristics help in the estimation of age, sex, race, socio-economic status, personal habits, oral and systemic health, occupation and dietary status of the person. The maintenance of teeth and type of prosthetic replacements and restorative materials indicate the socioeconomic status of an individual. Staining and discoloration of teeth can indicate habits like smoking and tobacco chewing. Eating disorders will show characteristic erosive changes on the teeth. Tooth defects and wear pattern characteristic for a specific profession as seen in shoemakers, carpenters and musicians holding objects in their mouth can also give vital information [3]. This article will focus on the methods to determine the identity of an individual vis à vis tooth characteristics.

\section{Age Determination}

Age changes can be observed in teeth such as enamel wear, secondary dentin apposition, root resorption, cementum apposition, root transparency, amino acid racemization and discoloration [4]. Individual teeth erupt into the oral cavity in a chronological sequence that is less reliable than the developmental status, however, in younger people; a reasonable determination of age at death is possible from this feature alone. Radiographs of the jaws will indicate the extent of mineralization within each individual tooth type, enabling age at death to be determined [5].

\section{Dentin translucency}

As the age progresses the dentinal tubules within the root apex become progressively mineralized. This mineralization alters the refractive index of the dentin, rendering it transparent when examined microscopically. Gustafson [6] was the first to emphasize the importance of translucency of root dentin in age determination of teeth in forensic investigation. Miles [7] found that root translucency is directly proportional to age of a person making it one of the most reliable factors in age determination.

\section{SEM study}

Scanning Electron Microscopic (SEM) examination is a vital tool for estimating the age as it helps in the assessment of root dentin translucency. It can also be used to confirm the presence of striations in tooth enamel and dentin due to past dental restorations [8].

\section{Cementum annulations}

Acellular cementu is the first cementum formed covering approximately the cervical third or half of the root surface before the tooth reaches the occlusal plane. Once the tooth reaches the occlusal plane, cellular cementum consisting of cementocytes is formed in the apical portion of the root in order to compensate for tooth eruption [9]. Both acellular and cellular cementum is arranged in lamellae called annulations separated by incremental lines. These annulations appear to correlate with the age of the root of the tooth. Acellular cementum being in the cervical area is less influenced by environmental factors and stresses and hence can estimate the age better than cellular cementum [10].

\section{Amino acid racemization}

Amino acids are built into the collagen as optically pure enantiomers of aspartic acid. Therefore aspartic acid exists in two different configurations viz "D" or "L" which are mirror images of each other. In general, living organs are composed of L-form of amino acids. After death of an individual the ratio of $\mathrm{D}$ to $\mathrm{L}$ increases with the increase in $\mathrm{D}$ form of amino acids by a process known as racemization. Thus,

${ }^{*}$ Corresponding author: Dr. Neha Jain, Manav Rachna Dental College, DelhiSurajkund Road, Sector-43, Faridabad, India, Tel: 01244015343, 9818095343; E-mail: nejamaverick@gmail.com

Received September 26, 2013; Accepted October 24, 2013; Published October 26, 2013

Citation: Jain N (2013) Tooth-A Key Aid in Establishing Identity of Deceased Individuals. Dentistry 3: 165. doi:10.4172/2161-1122.1000165

Copyright: (c) 2013 Jain N. This is an open-access article distributed under the terms of the Creative Commons Attribution License, which permits unrestricted use, distribution, and reproduction in any medium, provided the original author and source are credited. 
measuring the ratio of $\mathrm{D}$ to $\mathrm{L}$ in a sample helps in estimating the time elapsed since the death of the individual [11].

\section{Root resorption}

External root resorption can occur physiologically in a tooth due to masticatory forces acting in due course of life. Hence root length can also be considered as a useful attribute to estimate the chronological age of an adult [12].

\section{Sex Determination}

Teeth aid in determining the sex of the deceased bodies mutilated beyond recognition. Tooth size and morphology differ among males and females and with the advent of sex chromosome analysis sex determination has become more precise.

\section{Barr Bodies}

Remnants of cells from fragments of teeth may be examined for sex determination. It can be determined by using $\mathrm{X}$ and $\mathrm{Y}$ chromosomes in the cells which are inactive. $\mathrm{X}$ chromatin in its inactivated form is present as a mass against the nuclear membrane in females known as Barr body as it was first named by Barr and Bertem (1949). These are absent in males. Similarly F bodies in Y chromosome can be studied for sex determination of males. For accurate diagnosis, Barr bodies should be more than $6 \%$ and F-bodies should be up to $4 \%$ until a period of 4 weeks since death [13]. The only limitation for the use of this method is that any chromosomal anomaly can give negative or false positive results [14].

\section{PCR analysis}

The polymerase chain reaction (PCR) generates copies of a target sequence of DNA exponentially allowing analysis of even trace amount of DNA. Murakami et al. [15] studied sex determination using PCR on tooth material from the viewpoint of forensic medicine and found it to be a highly sensitive method. Hanaoka and Minaguchi [16] found PCR amplification of X and Y chromosome specific DNA sequences from tooth remnants a very precise method for sex determination.

\section{Amelogenin}

Amelogenin is an important matrix protein found in the human enamel essential for normal tooth development. Two amelogenin specific AMEL genes are present one on $\mathrm{X}$ chromosome and another on $\mathrm{Y}$ chromosome. Thus by amplifying $\mathrm{X}$ and $\mathrm{Y}$ specific amelogenin sequences sex can be determined from very small samples of DNA using PCR technique [17]. However primer binding site mutations or deletions of sections of the Y-chromosome can give incongruous results [18].

\section{Tooth dimorphism}

The morphological differences in male and female tooth forms can provide vital information in sex determination. Anderson and Thompson [19] studied canine dimorphism and found that mandibular canine width was greater in males than in females. Radiographic measurements of root length and crown diameter of mandibular permanent teeth can also aid in determining sex of the person [17].

\section{Race Determination}

It is difficult to recognize the inherited racial characteristics in a deceased individual as they get altered by the environmental factors during the growth process. However varying tooth morphology can separate Caucasoid, Negroid, and Mongoloid racial groups to a certain extent.

\section{Mongoloid group}

The incisors have deep lingual fossa formed by accentuated marginal ridges and prominent cingulum. The teeth are 'shovel' or 'scoop' shaped. The premolar may display tubercle, usually on the buccal cusp. This tooth is known as Leong's premolar and this condition is known as Den's Evaginatus. Taurodontism which is a dental anomaly in which body of the tooth is enlarged at the expense of roots is also commonly seen. Here the bifurcations or trifurcations occur near the apices of the roots. The cusp of Carabelli is absent in Mongoloids [20]. Mongoloid teeth are the largest in size in comparison with those of Negroids and Caucasoids. Protostylids, which are accessory cusps/tubercles that occur in the mesio-buccal surface of mandibular molars, occur with the highest frequency.

\section{Caucasoid group}

The anterior teeth of Caucasoids are 'chisel- shaped' and are smaller in size with a smooth lingual surface. The maxillary lateral incisor forms are usually peg- shaped [21]. Cusp of carabelli is present in maxillary molars.

\section{Negroid group}

Negroids have an increased tendency for the prevalence of supernumerary teeth. Tuberculum Intermedium which is an extra lingual cusp between the disto-lingual and mesio-lingual cusp of mandibular first molar is also very commonly seen in Negroids.

\section{DNA Analysis}

Teeth are an excellent source of DNA even after a long time after the death of an individual. With the application of PCR amplification even a small amount of DNA can be multiplied and compared with parents' or siblings' DNA samples. Tooth provides two types of DNA samples:

- Genomic DNA

- Mitochondrial DNA

This technique is very useful especially when other methods of dental profiling do not give enough information related to the identity of the person.

\section{Discussion}

A dental profile is unique to a person making it valuable in cases lacking any other evidence. The conventional techniques have been very helpful but they do not confirm the identity of the deceased. With the advancement in the methods of postmortem identification it has become easier to identify victims who do not have antemortem dental records. Though these new methods give vital information but still more research is required in this field. Methods for age and race determination are not confirmatory and foolproof. Also the methods for sex determination are very technique sensitive and need expertise. These methods are still at infancy stage in India and there is not enough expertise in this field. More research in this field will make it a vital tool in resolving many long- terms pending cases due to lack of evidence.

\section{Conclusion}

Dentistry has an important role to play in the identification of the victims of homicides, accidents or mass disasters. The uniqueness of the dental tissue can give an impetus to a forensic investigation lacking any 
other significant evidence. The development of more precise methods to collect the dental evidence has gradually made the field of odontology indispensible to forensic science.

\section{References}

1. Holden JL, Clement JG, Phakey PP (1995) Age and temperature related changes to the ultrastructure and composition of human bone mineral. J Bone Miner Res 10: 1400-1409.

2. Pretty IA, Sweet $D$ (2001) A look at forensic dentistry-Part 1: The role of teeth in the determination of human identity. Br Dent J 190: 359-366.

3. Vodanovic M, Brkić H (2012) Dental profiling in forensic sciences. Rad 514 Medical Sciences 38: 153-162.

4. Prince DA, Konigsberg LW (2008) New formulae for estimating age-at-death in the Balkans utilizing Lamendin's dental technique and Bayesian analysis. J Forensic Sci 53: 578-587.

5. Whittake DK, Llewelyn DR, Jones RW (1975) Sex determination form necrotic pulpal tissue. Br Dent J 139: 403-405.

6. Gustafson G (1947) Microscopic examination of teeth as a means of identification in forensic medicine. J Am Dent Assco 35: 720-724.

7. Miles AE (1976) Age changes in dental tissues- Scientific foundations of dentistry. William Heinemann Medical Books Ltd, London.

8. Stavrianos C, Stavrianou I, Dietrich E, Kafas P (2009) Methods for human identification in Forensic Dentistry: A Review. The Internet J Forensic Science.

9. Carranza FA (2001) Clinical periodontology. (8thedn), WB Saunders.

10. Charles DK, Condon K, Cheverud JM, Buikstra JE (1986) Cementum annulation and age determination in Homo sapiens. I. Tooth variability and observer error. Am J Phys Anthropol 71: 311-320.
11. Yamamoto T, Ohtani $S$ (2012) Estimation of chronological age from the racemization rate of $\mathrm{L}$ - and $\mathrm{D}$-aspartic acid: how to completely separate enantiomers from dentin. Methods Mol Biol 794: 265-272.

12. Kvaal SI, Kolltveit KM, Thomsen IO, Solheim T (1995) Age estimation of adults from dental radiographs. Forensic Sci Int 74:175-185.

13. Das N (2004) Sex determination from pulpal tissue. J Indian Acad Forensic Med 26: 971-973.

14. Galdames IS, Henriquez IR, Cantin M (2010) Sex chromatin in dental pulp. Performance of diagnosis test and gold standard generation. Int J Morphol 28 : 1093-1096.

15. Murakami H, Yamamoto Y, Yoshitome K, Ono T, Okamoto O, et al. (2000) Forensic study of sex determination using PCR on teeth samples. Acta Med Okayama 54: 21-32.

16. Hanaoka Y, Minaguchi K (1996) Sex determination from blood and teeth by PCR amplification of the alphoid satellite family. J Foren Sci 41: 855-858.

17. Dayal PK (1998) Textbook of Forensic Odontology, (1stedn), Paras Medical Publishers.

18. Thangaraj K, Reddy AG, Singh $L$ (2002) Is the amelogenin gene reliable for gender identification in forensic casework and prenatal diagnosis? Int $\mathrm{J}$ Legal Med 116: 121-123.

19. Anderson DL, Thompson GW (1973) Inter relationships and sex differences of dental and skeletal measurements. J Dent Res 52: 431-438.

20. Yaacob H, Narnbiar P, Naidu M (1996) Racial characteristics of human teeth with special emphasis on the Mongoloid dentition. Malaysian J Pathol 18: 1-7.

21. Dhalberg AA (1963) Dental traits as identification tools. Dent Prog 3: 155-160. 